\title{
Entre nuestras urgencias y sus deseos, la escucha
}

\section{Between our needs and their desires, listening}

\author{
J. Eduardo Sierra Nieto ${ }^{1}$
}

Recibido: 7 de julio de 2019 Aceptado: 15 de julio 2019 Publicado: 31 de julio de 2019

To cite this article: Sierra, J. E. (2019). Entre nuestras urgencias y sus deseos, la escucha.

Márgenes, Revista de Educación de la Universidad de Málaga, o (0), 119-122

DOI: http://dx.doi.org/10.24310/mgnmar.voio.6615

\section{${ }^{1}$ J. Eduardo Sierra Nieto}

Departamento de Teoría e Historia de la Educación y MIDE,

Facultad de Educación, Universidad de Málaga

esierra@uma.es

Twitter: @edukrator

https://uma.academia.edu/JEduardoSierraNieto

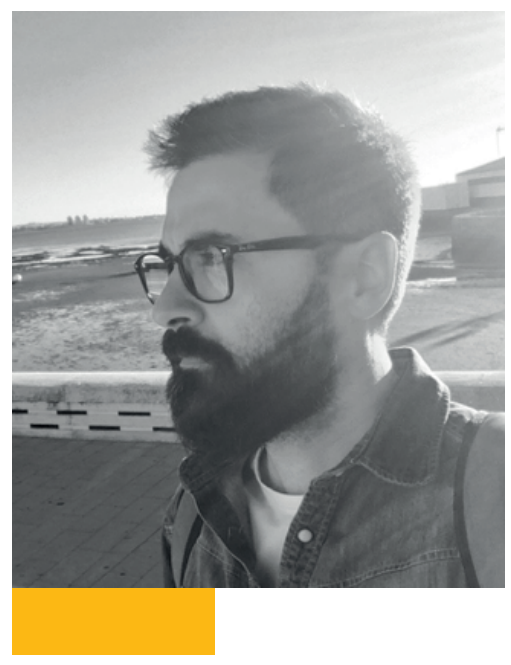

\section{RESUMEN}

Ser profesor, como ser padre, supone mantener una relación estrecha y de influencia con la infancia. Sin embargo, nuestros modos de vida no nos ayudan a tener una presencia consciente y diligente en nuestras relaciones con niños y jóvenes. En un tono autoreflexivo, el texto nos invita a considerar que, como adultos, hemos de aminorar la marcha para así escuchar, en un sentido pedagógico más pleno, a nuestros estudiantes y a nuestros hijos.

Palabras clave: pedagogía de la escucha; relación educativa; paternidad

\begin{abstract}
Being a teacher, like being a father, means maintaining a close and influential relationship with childhood. However, our ways of life do not help us to have a conscious and diligent presence in our relationships with children and young people. In a selfreflective tone, the text invites us to consider that, as adults, we must slow down in order to listen, in a more pedagogical sense, to our students and our children.
\end{abstract}

Keywords: pedagogy of listening; educational relationship; fatherhood 
¿Qué les dirá esa pregunta a nuestros hijos de nosotros? ¿Cómo viven, sienten y elaboran su jornada escolar? Y también, ¿qué es aprender en "su cabeza" (jen su cuerpo!)?
Imaginen por un momento esa típica escena diaria en la que una madre o un padre espera a alguno de sus hijos a la salida del colegio: "Trae aquí la mochila. ¿Te comiste el bocadillo? ¿Tienes deberes?". Nuestros hijos, con el pelo alborotado y algún churrete, miran para otro lado mientras tratan de proponernos otras conversaciones con más interés para ellos: "Mira el cromo que me han cambiado. Me caí y se me abrió la herida de la rodilla. Álvaro vomitó en la hora de mates". Y es que nuestras preguntas y sus historias suelen tener difícil encaje.

Es cierto que las dos de la tarde, en especial a final de curso (que es cuando escribo), no son unas horas proclives al encuentro, a la sintonía. El tráfico, el calor, las prisas por comprar el pan y sentarse a descansar (solo un rato) antes de continuar la tarde que amenaza asfixiante, son un duro rival para la charla pausada, para la presencia; en definitiva, para la escucha.

Aún así, diría que la cosa no depende en exclusiva de que estemos a mitad de junio y el calor nos atosigue. Más bien, diría, tiene que ver con dónde tenemos la cabeza (y el cuerpo) grandes y pequeños; y con lo que nos cuesta (estoy pensando en las personas adultas) atemperar nuestras urgencias para acompasarnos con los sentidos y deseos de los más pequeños.

Seguro que reconocerán también la irrefrenable necesidad que, de camino a casa, solemos sentir por formularles esa pregunta tan manida como recurrente de la que sin embargo pocos escapamos: ¿Qué has aprendido hoy?

¿Qué nos dice esa pregunta de nosotros, adultos, respecto de a qué creemos que van a la escuela, qué se hace allí y qué les ocurre? ¿Qué es aprender en "nuestra cabeza", desde nuestras prioridades, demandas y aspiraciones? Pensando mientras escribo, me animo a darle la vuelta a la cuestión y trato de considerarlo desde el lado de las criaturas. ¿Qué les dirá esa pregunta a nuestros hijos de nosotros? ¿Cómo viven, sienten y elaboran su jornada escolar? Y también, ¿qué es aprender en "su cabeza" (ien su cuerpo!)?

En la relación con mi hijo (9 años) algunos días doy un rodeo (mi mente de "profe" me pide que sea menos in- 
H I S T O R I A S M Í N I M A S

quisitivo) y le pregunto simplemente que qué tal el día. Una vez lanzada la pregunta, llega la respuesta estrella: bien (hasta ahí. Ni una palabra más). Pero como en casa ya sabemos que "bien" no es una respuesta" (les invito a que vean la película "Captain Fantastic" para captar la hondura de esa máxima familiar), le pido que se extienda un poquito. En ese momento percibo que nos amenaza de nuevo el desencuentro. Puede que no entre nosotros (quizá sí) sino entre lo que hay en su cabeza y lo que hay en la mía; entre lo que imagino que es haber estado cinco horas en la escuela y lo que para él ha podido significar como vida vivida.

Vale, me digo, no insistas. Ya deberías saber, me vuelvo a decir, que mejor no preguntar; que las mejores respuestas vienen solas, cuando de pronto, como la otra tarde mientras estábamos en el supermercado, me sorprendió con una reflexión inquietante pero afiladísima sobre nuestras formas de vida y la sostenibilidad del planeta: "Papá, no entiendo por qué si existen los coches eléctricos seguimos utilizando los de gasolina. Es que la seño ha dicho que si seguimos contaminando se derretirán los polos y lo inundarán todo. Y aunque será dentro de muchos años, puede que muramos ahogados".

En esa situación mi mente de "profe" se apresura a intervenir otra vez: ¿Y por qué no me contaste esto cuando, a la salida del colegio, te pregunté que qué habías aprendido? Entonces, entre sorprendido y admirado, me digo: ¿cómo es posible que relacione de una manera tan reflexiva algunas de nuestras conversaciones con los temas abordados en la escuela, pero no sepa decirme qué aprendió tal o cual día?

Así que ahí voy, tratando de aprender a esperar, a escuchar más. Y tratando de considerar en mi relación con él aquello que para mí mismo sí que reconozco: que aprender sucede cuando sucede y no cuando uno (por lo general el "otro" adulto) quiere.

¿Y si "aprender" es esto, una pregunta que súbitamente germina en el interior de alguien y le invita a preguntar(se), a dialogar, "cuando toca"? ¿No será que ser adulto en relación con la infancia tiene más que ver con aguardar en silencio que con atosigar con nuestra cháchara? ¿Y si en definitiva se trata, como ya

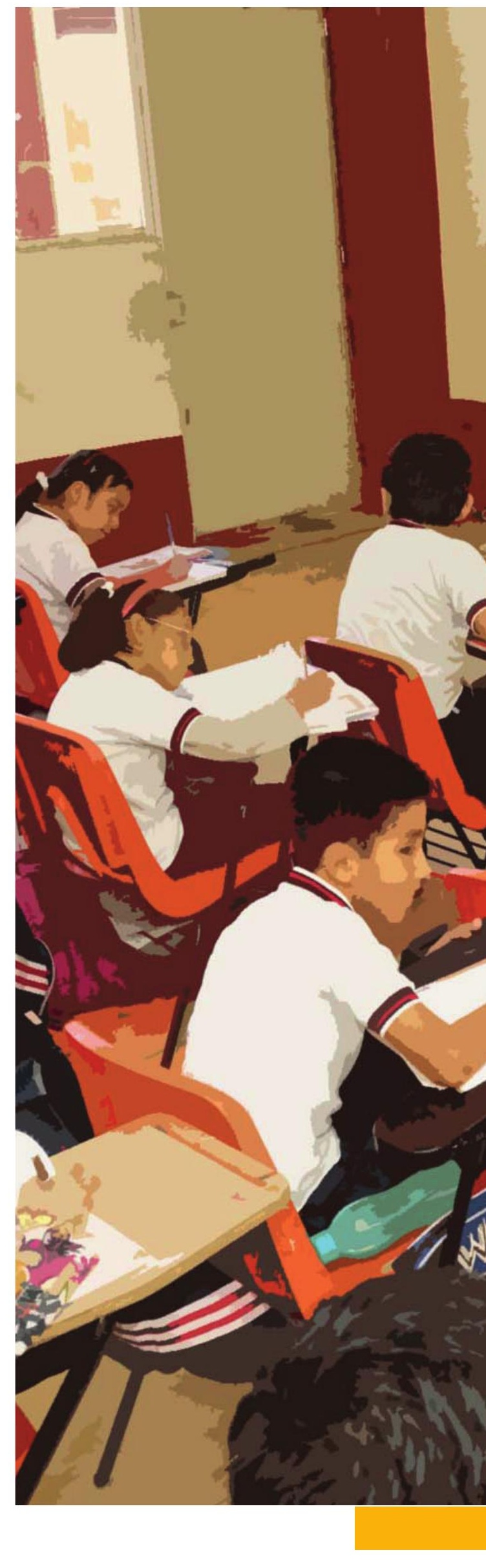




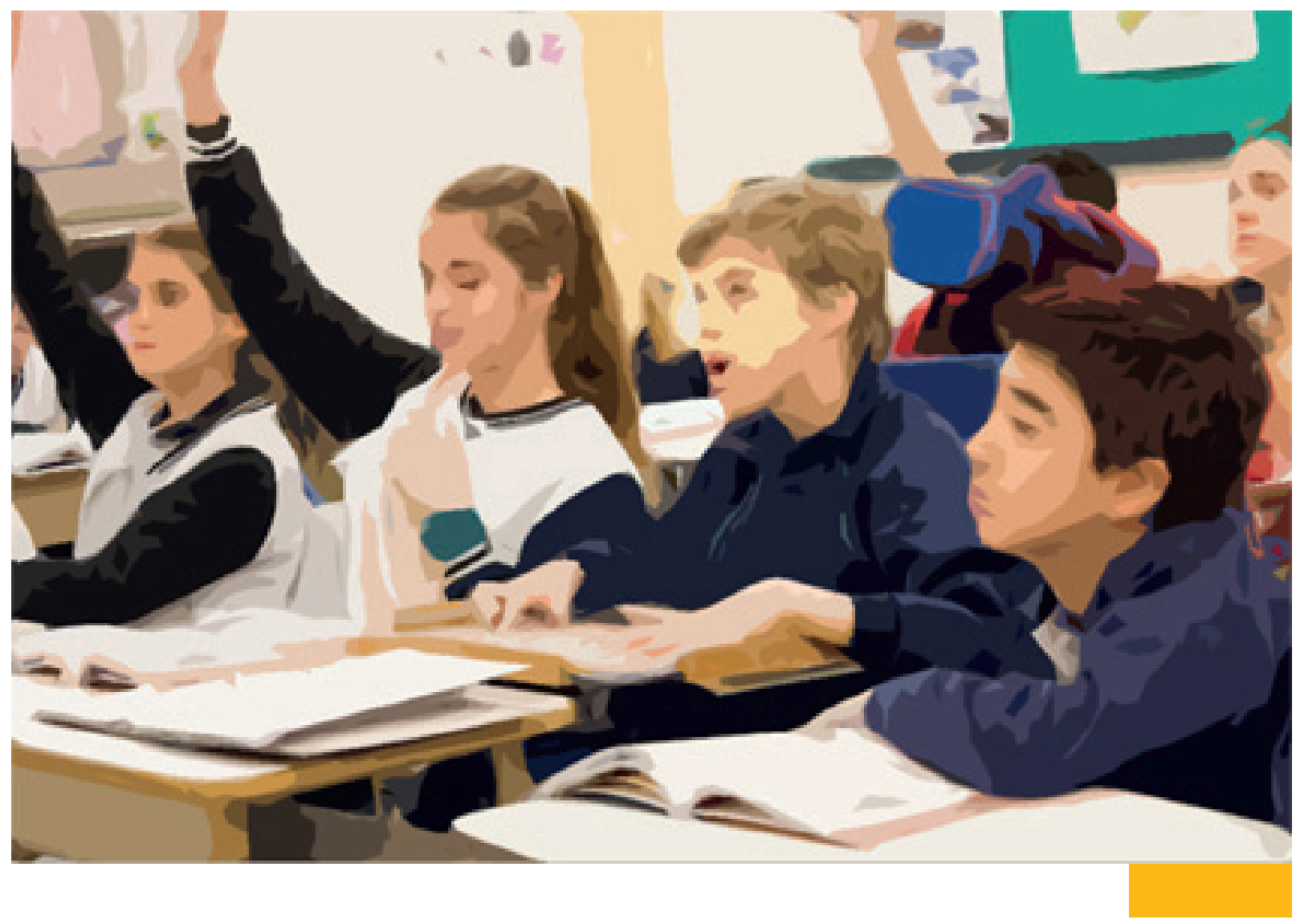

¿ ¿Y si "aprender" es esto, una pregunta que súbitamente germina en el interior de alguien y le invita a preguntar(se), a dialogar, "cuando toca"? nos invitó a considerar Gianni Rodari, de no perder nuestra oreja verde de niño para poder así escuchar el mundo como ellos lo hacen o, al menos, para tomar más en serio cómo viven, sienten y aprenden los más pequeños?

Les seguiré contando. 